[Article]

\title{
nc-Si:H/c-Si 硅异质结太阳电池中本征硅薄膜钝化层的优化
}

\author{
乔 治 ${ }^{1,2}$ 解新建 ${ }^{1}$ 薛俊明 ${ }^{3}$ 刘 辉 ${ }^{1}$ 梁李敏 ${ }^{1}$ 郝秋艳 ${ }^{1}$ 刘彩池 ${ }^{1, *}$ \\ ('河北工业大学光电功能晶体材料河北省工程实验室, 天津 300130; ${ }^{2}$ 石家庄铁道大学数理系应用 \\ 物理研究所, 石家庄 050043; 3河北汉盛光电科技有限公司, 河北衡水 053000)
}

\begin{abstract}
摘要: 采用射频等离子体增强化学气相沉积(RF-PECVD)法在低温、低功率的条件下制备了一系列本征硅薄 膜, 研究了硅烷浓度 $\left(C_{S}\right)$ 对薄膜微结构、光电特性及表面钝化性能的影响. 将本征硅薄膜作为钝化层应用到氢 化纳米晶硅/晶硅(nc-Si:H/c-Si)硅异质结(SHJ)太阳电池中, 研究了硅烷浓度和薄膜厚度对电池性能的影响. 实 验发现: 随着硅烷浓度的降低, 本征硅薄膜的晶化率、氢含量、结构因子、光学带隙和光敏性等都在过渡区急剧 变化; 本征硅薄膜的钝化性能由薄膜的氢含量及氢的成键方式决定. 靠近过渡区的薄膜具有较好的致密性和光 敏性, 氢含量最高, 带隙态密度低, 且主要以 $\mathrm{SiH}$ 形式成键, 对硅片表现出优异的针化性能, 使电池的开路电压 大幅提高. 但是, 当薄膜的厚度过小时, 会严重影响其钝化质量. 本实验中, 沉积本征硅薄膜的最优硅烷浓度为 $6 \%$ (摩尔分数), 且当薄膜厚度为 $8 \mathrm{~nm}$ 时, 所制备电池的性能最好. 实验最终获得了开路电压为 $672 \mathrm{mV}$, 短路 电流密度为 $35.1 \mathrm{~mA} \cdot \mathrm{cm}^{-2}$, 填充因子为 0.73 , 效率为 $17.3 \%$ 的 nc-Si:H/c-Si SHJ 太阳电池.
\end{abstract}

关键词: 本征硅薄膜; 射频等离子体增强化学气相沉积; 界面钝化; 少子寿命; 硅异质结太阳电池

中图分类号: 0649

\section{Optimization of Intrinsic Silicon Passivation Layers in nc-Si:H/c-Si Silicon Heterojunction Solar Cells}

\author{
QIAO Zhi ${ }^{1,2} \quad$ XIE Xin-Jian ${ }^{1} \quad$ XUE Jun-Ming ${ }^{3} \quad$ LIU Hui ${ }^{1}$ \\ LIANG Li-Min ${ }^{1} \quad$ HAO Qiu-Yan ${ }^{1} \quad$ LIU Cai-Chi ${ }^{1, *}$
}

('Engineering Laboratory of Photoelectric Functional Crystals in Hebei Province, Hebei University of Technology, Tianjin 300130 ,

P. R. China; ${ }^{2}$ Institue of Applied Physics, Department of Mathematics and Physics, Shijiazhuang Tiedao University, Shijiazhuang 050043, P. R. China; ${ }^{3}$ China Hisun PV Technology Co., Ltd., Hengshui 053000, Hebei Province, P. R. China)

\begin{abstract}
A series of intrinsic silicon thin films were prepared using radio-frequency plasma-enhanced chemical vapor deposition (RF-PECVD) at low temperature and low power density. We investigated the influence of silane concentration $\left(C_{s}\right)$ on the structural, optical, and electronic properties, and passivation quality of the intrinsic silicon films, and the performances of hydrogenated nanocrystalline silicon/crystalline silicon (nc-Si:H/ $\mathrm{c}-\mathrm{Si}$ ) silicon heterojunction ( $\mathrm{SHJ}$ ) solar cells. The results show that with decreasing silane concentration, substantial changes in the crystalline volume fraction, hydrogen concentration, structure factor, optical bandgap, and photosensitivity of the film take place in the transition zone. The passivation quality of intrinsic silicon thin films is decided by the hydrogen content and bonding structure of the film. Films close to the transition zone show good compactness and photosensitivities, high hydrogen content, and low state densities, and contain abundant $\mathrm{SiH}$ bonds. The films provide excellent passivation for c-Si surfaces and significantly enhance the open-circuit voltages of nc-Si:H/c-Si SHJ solar cells. However, the passivation quality deteriorates seriously when the film is too thin. In this work, the optimum silane concentration was found to be $6 \%$ (molar fraction).
\end{abstract}

Received: January 5, 2015; Revised: April 9, 2015; Published on Web: April 14, 2015.

"Corresponding author. Email: ccliu@hebut.edu.cn; Tel: +86-22-26526293.

The project was supported by the National High Technology Research and Development Program of China (863) (2012AA050301) and Scientific Research Program of Hebei Education Department, China (Z2010304).

国家高技术研究发展计划项目(863) (2012AA050301)和河北省教育厅科研计划项目(Z2010304)资助

(C) Editorial office of Acta Physico-Chimica Sinica 
By optimizing the film thickness of the passivation layers with $C_{s}=6 \%$, we obtained an nc-Si:H/c-Si SHJ solar cell with an open-circuit voltage of $672 \mathrm{mV}$, short-circuit current density of $35.1 \mathrm{~mA} \cdot \mathrm{cm}^{-2}$, fill factor of 0.73 , and efficiency of $17.3 \%$.

Key Words: Intrinsic silicon thin film; Radio-frequency plasma enhanced chemical vapor deposition; Interface passivation; Minority carrier lifetime; Silicon heterojunction solar cell

\section{1 引 言}

硅异质结(SHJ)太阳电池因具有工艺温度低、转 换效率高、电池稳定性好及温度系数低等特点而备 受国内外研究人员关注. 2014 年, 日本松下公司在 $n$ 型 $\mathrm{Cz}-\mathrm{Si}$ 单晶祄底上成功制备出转换效率为 $25.6 \%$ 的高效背接触 SHJ 太阳电池, 刷新了澳大利亚新南 威尔士大学 1999 年创下的晶硅电池 $25.0 \%$ 的纪录. ${ }^{1,2}$ 松下高效 SHJ 电池的关键技术之一是在晶硅祄底和 掺杂非晶硅薄膜之间插入一层极薄的高质量本征 氢化非晶硅(a-Si:H(i))薄膜. 一般情况下, 硅片表面 存在有大量的界面态缺陷, 主要由硅片表面的大量 悬挂键缺陷引入, 是有效的光生载流子复合中心. 实验和理论结果都表明, ${ }^{3-7}$ 当界面态缺陷密度 $D_{\mathrm{it}}>$ $10^{11} \mathrm{~cm}^{-2} \cdot \mathrm{eV}^{-1}$ 时, 电池的开路电压、填充因子和转 换效率就会急剧下降. 借助 a-Si:H(i)薄膜优异的针 化能力, 对硅片表面的悬挂键缺陷进行有效钝化, 大大降低少数载流子在异质结界面的复合速率, 可 使 SHJ 电池的开路电压达到 $700 \mathrm{mV}$ 以上, 电池效率 得到大幅提升.

然而, 由于 $\mathrm{SHJ}$ 电池中 $\mathrm{a}-\mathrm{Si}: \mathrm{H}(\mathrm{i})$ 钝化层的厚度 很薄, 一般要求控制在 5-15 nm, 因此要得到薄而均 匀且结构特性和光电特性优良的高质量 $\mathrm{a}-\mathrm{Si}$ :H(i)针 化层, 需要严格控制薄膜沉积的工艺参数. 同时, 在 采用 RF-PECVD法制备 a-Si:H(i)薄膜时, 为避免离 子轰击对界面造成损伤要求沉积功率尽可能低, 为 避免外延硅生长而使薄膜的钝化质量降低则要求 沉积温度及氢稀释不宜过高, ${ }^{8-10}$ 因此沉积高质量 a$\mathrm{Si}: \mathrm{H}(\mathrm{i})$ 针化层的工艺窗口很窄. 由于松下公司在技 术和工艺参数上对外都严格保密, 至今尚无一家研 究机构能够达到或重复其 SHJ 电池的高效率. 因此, 优化 a-Si:H(i) 薄膜的钝化性能, 提高异质结的界面 质量, 一直是各国研究机构函待攻关的技术难题.

本课题组前期以掺硼纳米晶硅 $(\mathrm{nc}-\mathrm{Si}: \mathrm{H}(p))$ 为窗 口层, 初步研发了 $\mathrm{nc}-\mathrm{Si}: \mathrm{H}(p) / \mathrm{c}-\mathrm{Si}(n)$ ( $p$ 型纳米晶硅 $/ n$ 型晶硅) SHJ 太阳电池. ${ }^{11}$ 为进一步提高电池性能, 本 文用 RF-PECVD 在低温、低功率的条件下制备了一 系列不同硅烷浓度的本征硅薄膜, 研究了硅烷浓度
对薄膜的微结构、光电性能及表面钝化性能的影 响. 将本征硅薄膜作为针化层应用到 $\mathrm{nc}-\mathrm{Si}: \mathrm{H}(p) / \mathrm{c}-\mathrm{Si}$ (n) SHJ 太阳电池中, 研究了硅烷浓度和薄膜厚度对 电池性能的影响. 通过优化, 制备出了效率为 $17.3 \%$ 的 nc-Si: $\mathrm{H}(p) / \mathrm{c}-\mathrm{Si}(n)$ 异质结太阳电池.

\section{2 实验部分}

\section{1 本征硅薄膜的制备与表征}

实验采用电容耦合式 Cluster 型 RF- PECVD (13.56 MHz) 制备本征硅薄膜, 系统的本底真空为 $8 \times$ $10^{-6} \mathrm{~Pa}$, 电极间距 $2 \mathrm{~cm}$. 以纯度为 $99.9999 \%$ 的高纯 $\mathrm{SiH}_{4}$ 和 $\mathrm{H}_{2}$ 为反应源气体, 气体总流量为 $100 \mathrm{~cm}^{3}$. $\mathrm{min}^{-1}$, 沉积压强为 $106 \mathrm{~Pa}$, 功率密度为 $30 \mathrm{~mW} \cdot \mathrm{cm}^{-2}$, 祄底温度为 $150{ }^{\circ} \mathrm{C}$, 硅烷浓度 $\left(C_{\mathrm{S}}=\mathrm{SiH}_{4}:\left(\mathrm{SiH}_{4}+\mathrm{H}_{2}\right)\right)$ 的 变化范围为 $1 \%-10 \%$. 将本征硅薄膜同时沉积在 Corning7095 玻璃和抛光硅片祄底上 $(8-13 \Omega \cdot \mathrm{cm}, p$ 型) 以研究其光电特性和结构特性, Corning7095 玻 璃祄底用于样品的透过、电导率和 Raman 测试, 抛 光硅片祄底用于样品的傅里叶变换红外(FTIR)光谱 测试, 所有样品的厚度均为 $300 \mathrm{~nm}$ 左右. 样品的厚 度由Ångstrom SR300 反射式膜厚仪(美国Ångstrom Sun Technologies 公司) 测定, 透过率通过 7-SCSpecIII太阳能电池光谱测试系统(北京赛凡光电仪器有 限公司) 获得, 并通过 Tauc 作图法 ${ }^{12}$ 确定薄膜的光学 带隙. 本征硅薄膜的电导率采用共面铝电极法通过 Keithley6517B 型静电计(美国 Keithley 公司)测量电 流. 采用EQUINOX55-FRA160/s 型傅里叶变换拉曼 光谱仪 (FT- Raman, 德国 Bruker 公司, 激光波长 $514.5 \mathrm{~nm}$, 测量功率 $20 \mathrm{~mW}$ ) 和 SPECTRUM-GX 傅 里叶变换红外光谱仪(美国 Perkin Elmer 公司)表征 样品的结构特性. 在制线硅片的前后表面沉积上等 厚的本征硅薄膜, 运用 2013WJ-100A 型微波光电导 寿命测试仪(广州市昆德科技有限公司)测试硅片的 少子寿命.

\section{$2.2 \mathrm{SHJ}$ 电池的制备与测试}

实验以本征硅薄膜为钝化层制备了一系列 nc$\mathrm{Si}: \mathrm{H}(p) / \mathrm{c}-\mathrm{Si}(n) \mathrm{SHJ}$ 太阳电池, 电池结构为 $\mathrm{Al} / \mathrm{ITO} /$ 
表 1 SHJ 电池中 $\mathbf{i}$ 层和 $p$ 层的沉积参数

Table 1 Deposition conditions for i- and p-layers in SHJ solar cells

\begin{tabular}{ccccccc}
\hline Layer & $P_{\mathrm{w}} /\left(\mathrm{mW} \cdot \mathrm{cm}^{-2}\right)$ & $p_{\mathrm{r}} / \mathrm{Pa}$ & $T_{\mathrm{s}}{ }^{\circ} \mathrm{C}$ & $C_{\mathrm{S}} / \%$ & $B_{\mathrm{S}} / \%$ & $d / \mathrm{nm}$ \\
\hline a-Si:H(i) & 30 & 106 & 150 & $1-10$ & - & $2-13$ \\
nc-Si:H $(p)$ & 75.6 & 80 & 200 & 1 & 0.3 & 20 \\
\hline
\end{tabular}

$P_{\mathrm{w}}$ : radio-frequency (RF) power density; $p_{\mathrm{r}}$ : pressure; $T_{\mathrm{s}}$ : substrate temperature; $C_{\mathrm{s}}$ : silane concentration; $B_{\mathrm{s}}$ : doping ratio of $\mathrm{B}_{2} \mathrm{H}_{6}$ to $\mathrm{SiH}_{4}$; $d$ : electrode distance

nc-Si:H $(p) / \mathrm{a}-\mathrm{Si}: \mathrm{H}(\mathrm{i}) / \mathrm{c}-\mathrm{Si}(n) / \mathrm{c}-\mathrm{Si}(n+) / \mathrm{Al}$. 电池祄底采 用太阳能级 $n$ 型制线 Cz-Si(100)硅片, 电阻率为 1-3 $\Omega \cdot \mathrm{cm}$, 厚度约为 $200 \mu \mathrm{m}$, 背面扩磷作为电池背场 (BSF). 实验首先用 RCA I 号液 $\left(\mathrm{NH}_{4} \mathrm{OH}: \mathrm{H}_{2} \mathrm{O}_{2}: \mathrm{H}_{2} \mathrm{O}=1\right.$ : $1: 5)$ 和 II 号液 $\left(\mathrm{HCl}: \mathrm{H}_{2} \mathrm{O}_{2}: \mathrm{H}_{2} \mathrm{O}=1: 1: 6\right)$ 清洗硅片, 去除 硅片表面的有机物及金属杂质沾污. 之后, 将硅片 放入 $5 \%$ 的 HF 溶液中浸泡 $60 \mathrm{~s}$, 去除表面上的氧化 层. 随后在氮气保护下将硅片快速装入 RF-PECVD 系统中, 防止在硅片表面生成有害的自然氧化层. 为防止交叉污染, 分别在独立腔室相继沉积本征硅 薄膜针化层 $\mathrm{a}-\mathrm{Si}: \mathrm{H}(\mathrm{i})$ 和窗口层 $\mathrm{nc}-\mathrm{Si}: \mathrm{H}(p)$, 沉积参数 如表 1 所示. 最后采用 JGP232 型磁控溅射镀膜设备 (沈阳新蓝天真空技术有限公司)在窗口层 $\mathrm{nc}-\mathrm{Si}: \mathrm{H}$ $(p)$ 和背场 $\mathrm{c}-\mathrm{Si}(n+)$ 上分别溅射 $80 \mathrm{~nm}$ 厚的氧化铟锡 (ITO) 薄膜, 并用 DM-300B 真空镀膜机 (北京北仪创 新真空技术有限责任公司)制备前后 $\mathrm{Al}$ 电极. 实验 通过 7-SCSpecIII 太阳能电池光谱测试系统, 在室温 下采用 $\mathrm{AM} 1.5,100 \mathrm{~mW} \cdot \mathrm{cm}^{-2}$ 的光照条件测试电池 的电流密度-电压 $(J-V)$ 特性曲线。

\section{3 结果与讨论}

\section{1 硅烷浓度对本征硅薄膜微结构的影响}

图 1 为不同硅烷浓度下所制得的本征硅薄膜的 Raman 散射图谱, 自下而上硅烷浓度依次降低. 从 图中可以看出, 对于硅烷浓度为 $10 \%$ 和 $8 \%$ 的样品, 其类横光学模(类 $\mathrm{TO}$ 模)仅在 $480.0 \mathrm{~cm}^{-1}$ 位置附近出 现了一个馒头峰(非晶相峰), 表现为典型的非晶硅 薄膜特征. 而当硅烷浓度减小为 $6 \%$ 时, 可以注意 到, 在非晶相峰的右端 $514.0 \mathrm{~cm}^{-1}$ 附近出现了一个 小的“肩膀”, 表明此时的材料仍基本呈非晶态, 但 是结构中开始有晶相成分出现. 随着硅烷浓度的进 一步降低, $480.0 \mathrm{~cm}^{-1}$ 附近的非晶峰逐渐减弱, 而晶 相峰的强度不断增强, 半高宽不断减小, 峰位从 $513.9 \mathrm{~cm}^{-1}$ 蓝移至 $518.1 \mathrm{~cm}^{-1}$, 表明薄膜的晶化程度 逐渐增强. 图 2 给出了硅烷浓度分别为 $6 \%$ 、5\%和

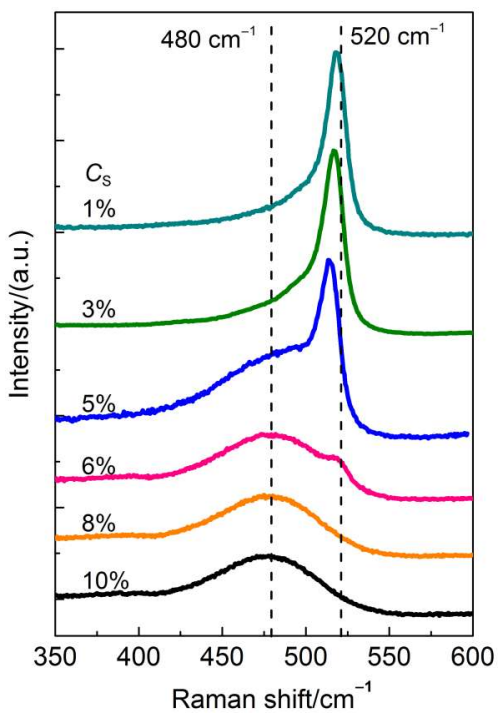

图 1 不同硅烷浓度 $\left(C_{\mathrm{s}}\right)$ 下薄膜的拉曼图谱

Fig.1 Raman spectra of films with different silane concentrations $\left(C_{\mathrm{s}}\right)$

$3 \%$ 样品的高斯拟合曲线, 可以看到拟合曲线与实验 数据点符合得非常好. 对于 5\%和 3\%的样品, 其类 $\mathrm{TO}$ 模采用三峰高斯拟合可分解为: 位于 $480.0 \mathrm{~cm}^{-1}$ 附近的非晶峰、 $500.0 \mathrm{~cm}^{-1}$ 附近的中间峰和 510.0$518.0 \mathrm{~cm}^{-1}$ 附近的纳米晶相峰. 从图 2 中可以很清楚 的看到, 薄膜各相结构随硅烷浓度的变化情况. 薄 膜的晶化率可由公式 $X_{\mathrm{C}}=\left(I_{\mathrm{c}}+I_{\mathrm{gb}}\right) /\left(I_{\mathrm{c}}+I_{\mathrm{gb}}+\eta I_{\mathrm{a}}\right) \times 100 \%$ 计 算得到, ${ }^{13}$ 式中 $I_{\mathrm{a}} 、 I_{\mathrm{c}} 、 I_{\mathrm{gb}}$ 分别表示非晶峰、晶相峰和中 间峰的散射强度, $\eta$ 为散射因子, 约为 1.0. 薄膜晶化 率随硅烷浓度的变化曲线见图 3. 由图可见, 当 $C_{\mathrm{s}}=$ $6 \%$ 时, 薄膜的晶化率 $X_{\mathrm{C}}$ 仅为 $4.5 \%$, 之后随着硅烷浓 度的降低, $X_{\mathrm{C}}$ 快速增加, 而当 $C_{\mathrm{S}}<3 \%$ 时, 薄膜的晶化 率趋于饱和. 薄膜中纳米晶粒的尺寸可由公式 $d=2 \pi$ $(\beta / \Delta \omega)^{1 / 2}$ 估算得到, ${ }^{14}$ 式中 $\Delta \omega$ 为拉曼散射谱中晶态峰 位与单晶硅峰位 $\left(521.5 \mathrm{~cm}^{-1}\right)$ 之差, $\beta$ 为常数, 取值为 $2.0 \mathrm{~nm}^{2} \cdot \mathrm{cm}^{-1}$. 经计算, 硅烷浓度分别为 $5 \% 、 3 \%$ 和

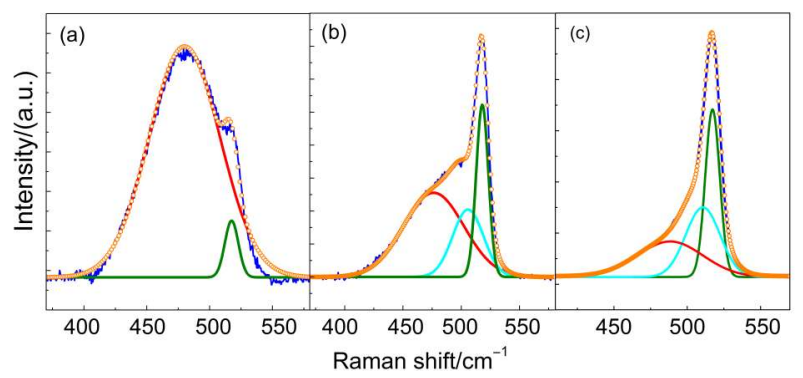

图 2 不同硅烷浓度下薄膜的高斯拟合曲线

Fig.2 Gaussian fitting curves of films with different silane concentrations

(a) $C_{\mathrm{S}}=6 \%$; (b) $C_{\mathrm{S}}=5 \%$; (c) $C_{\mathrm{S}}=3 \%$ 


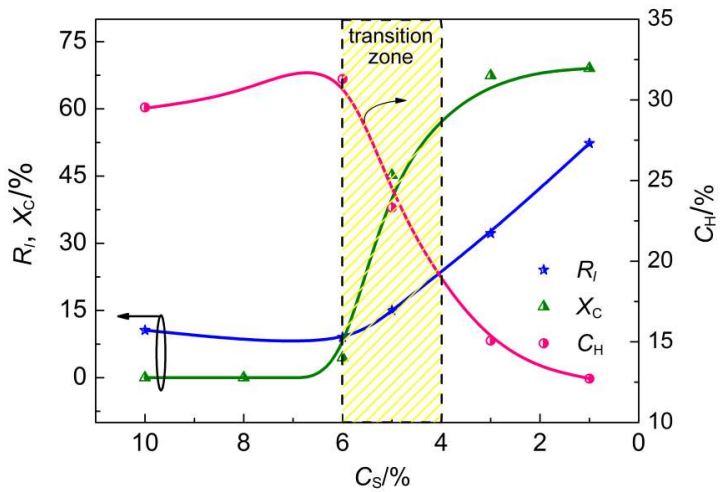

图 3 薄膜的结构因子 $\left(R_{I}\right)$, 氢含量 $\left(C_{\mathrm{H}}\right)$ 及晶化率 $\left(X_{\mathrm{C}}\right)$ 随硅烷浓度的变化

Fig.3 Structure factor $\left(R_{I}\right)$, hydrogen content $\left(C_{\mathrm{H}}\right)$, and crystalline volume fraction $\left(X_{\mathrm{C}}\right)$ of films with different silane concentrations

$1 \%$ 薄膜中的平均晶粒尺寸分别为 $3.2 、 4.3$ 和 4.8 $\mathrm{nm}$. 根据本征硅薄膜的晶化度随硅烷浓度的变化情 况，可以将其分为三个区: $C_{\mathrm{s}}>6 \%$ 的非晶区, $6 \%-4 \%$ 的过渡区及 $C_{\mathrm{S}}<3 \%$ 的纳晶区. 根据薄膜生长的“刻 蚀模型” ${ }^{15}$ 和 “表面扩散模型” ${ }^{16}$ 可知, 等离子体中的 活性氢原子 $\mathrm{H}$ 对薄膜的晶化发挥着非常重要的作 用. 随着硅烷浓度降低, 也即氢稀释的增加, 等离子 体中尤其是薄膜生长表面附近的的活性氢原子浓 度增加, 从而能够有效刻蚀掉薄膜中的 $\mathrm{Si}-\mathrm{H}, \mathrm{Si}-$ $\mathrm{Si}$ 弱键(非晶相模式), 利于晶格弛豫, 使新到达生长 表面的含硅粒子和离子在生长表面形成 $\mathrm{Si}-\mathrm{Si}$ 强键 (晶相模式)形成稳定的晶相结构, 促进薄膜晶化; 此 外, 在高氢稀释条件下, 薄膜的生长表面可被原子 氢充分地覆盖, 氢原子会饱和硅薄膜表面的硅悬挂 键, 同时释放一定的能量, 这两个作用都会增加反 应前驱物尤其是 $\mathrm{SiH}_{3}$ 在薄膜生长表面的扩散长度, 使其容易在薄膜表面找到能量较低的位置, 进而成 核生长.

图 4 为不同硅烷浓度下薄膜的 FTIR 图谱, 图中 位于 $630-640 \mathrm{~cm}^{-1} 、 880-890 \mathrm{~cm}^{-1}$ 和 $2000-2100 \mathrm{~cm}^{-1}$ 附近的吸收峰分别对应于硅-氢键合模式的摇摆模、 弯曲模和伸缩模. ${ }^{17}$ 从图中可以看出, 当硅烷浓度由 $10 \%$ 减小到 6\%时, 位于 $630-640 \mathrm{~cm}^{-1}$ 和 $2000-2100$ $\mathrm{cm}^{-1}$ 附近的吸收峰有所增强, 峰位基本保持不变; 之 后随着硅烷浓度的降低(氢稀释的增加), 峰强逐渐 降低, 摇摆模的峰位基本不变, 伸缩模的峰位则逐 渐由 2000 向 $2100 \mathrm{~cm}^{-1}$ 移动. 对伸缩模的吸收峰进 行高斯拟合, 可将谱线分解为峰位分别位于 2000 和 $2100 \mathrm{~cm}^{-1}$ 附近的两个高斯峰, 分别对应于非晶硅薄

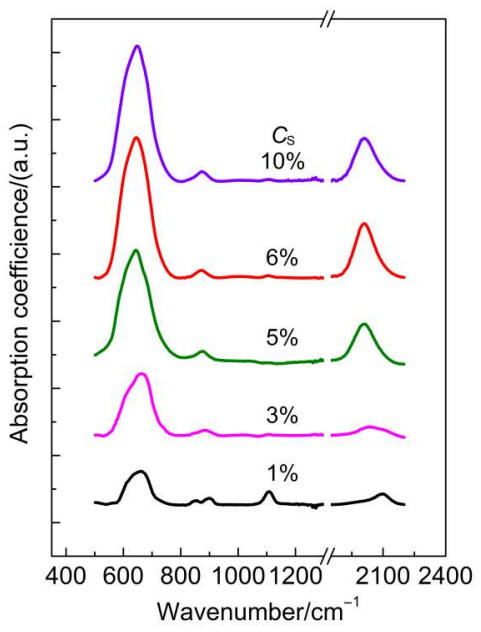

图 4 不同硅烷浓度下薄膜的傅里叶变换红外(FTIR)光谱

Fig.4 Fourier transform infrared (FTIR) spectra of films with different silane concentrations

膜内的 $\mathrm{SiH}$ 和 $\mathrm{SiH}_{2}$ 键, $\mathrm{SiH}_{2}$ 一般存在于非晶硅薄膜 内微空洞的内表面, $\mathrm{SiH}_{2}$ 越多表明薄膜内微空洞越 多, 薄膜越疏松. $2100 \mathrm{~cm}^{-1}$ 附近高斯峰的相对强度, $R_{I}=I_{2100} /\left(I_{2000}+I_{2100}\right)$, 即为薄膜的结构因子. 薄膜的氢含 量可利用 630-640 $\mathrm{cm}^{-1}$ 处摇摆模吸收峰的积分强度 通过下式计算得到: ${ }^{18}$

$$
\begin{aligned}
& C_{\mathrm{H}}=\frac{A_{640}}{N} I_{640} \\
& I_{640}=\int_{\omega_{1}}^{\omega_{2}} \frac{a(\omega)}{\omega} \mathrm{d} \omega
\end{aligned}
$$

式中, $A_{640}=1.6 \times 10^{19} \mathrm{~cm}^{-2}, N$ 为薄膜中硅原子与氢原 子的密度之和, 取 $N=5.0 \times 10^{22} \mathrm{~cm}^{-3}$. 薄膜的结构因子 及氢含量随硅烷浓度的变化曲线如图 3 所示. 从图 中可以看到, 在 $C_{\mathrm{s}}<6 \%$ 的非晶硅区, 随着硅烷浓度 的降低, $R_{I}$ 缓慢减小, $C_{\mathrm{H}}$ 逐渐增大, 且在 $C_{\mathrm{S}}=6 \%$ 附近, $R_{I}$ 和 $C_{\mathrm{H}}$ 分别达到最小值和最大值. $R_{I}$ 在非晶硅区随 硅烷浓度降低而逐渐减小, 说明薄膜逐渐由疏松变 得致密. 此外, 还可以看到, 在 6\%-4\%的过渡区, $R_{I}$ 和 $C_{\mathrm{H}}$ 都发生了急剧变化, $R_{I}$ 急剧增大, $C_{\mathrm{H}}$ 急剧减小, 这是薄膜处于过渡区的典型特征. ${ }^{19-21}$

\section{2 硅烷浓度对本征硅薄膜光电性能的影响}

图 5 为薄膜的光学带隙随硅烷浓度变化的曲 线. 可以看到, 当硅烷浓度由 $10 \%$ 降低到 $6 \%$ 时, 其 光学带隙由 $1.74 \mathrm{eV}$ 缓慢增加至 $1.77 \mathrm{eV}$. 由前面的 Raman 和 FTIR 分析可知, 在这个范围内, 硅薄膜处 于非晶态且薄膜中的氢含量增加, 氢的键入使得薄 膜材料的有序度提高, 带隙态密度降低, 价带顶下 降, 从而使薄膜的光学带隙提高. 当继续降低硅烷 浓度, 即 $C_{\mathrm{s}}<6 \%$ 时, 薄膜开始由非晶硅向纳米晶硅 




图 5 不同硅烷浓度下薄膜的光学带隙 $\left(\boldsymbol{E}_{\mathrm{opt}}\right)$

Fig.5 Optical band gap $\left(E_{\text {opt }}\right)$ of films with different silane concentrations

过渡, 薄膜的晶化率随硅烷浓度的降低急剧增加, 由于薄膜带尾展宽变小及量子限制效应, 薄膜的带 隙迅速增大. 可见, 薄膜的光学带隙与薄膜的晶化 程度密切相关, 该结果与文献 ${ }^{22-24}$ 报道的结果一致.

图 6 所示为薄膜的电导率及光敏性随硅烷浓度 的变化. 从图中可以看到, 随着硅烷浓度的降低, 薄 膜的光电导呈略微增大的趋势, 而暗电导和光敏性 的变化趋势相反, 但在三个区域: $C_{\mathrm{S}}>6 \%$ (非晶区), $6 \%-4 \%$ (过渡区), $C_{\mathrm{S}}<3 \%$ (纳晶区) 都呈现慢速-快速慢速的变化. 与纳米晶硅材料相比, 非晶硅材料具 有暗电导小、光敏性大的特点. 在 $C_{\mathrm{S}}=6 \%$ 时, 薄膜的 光敏性为 $1.5 \times 10^{4}$, 暗电导为 $1.8 \times 10^{-11} \mathrm{~S} \cdot \mathrm{cm}^{-1}$.

\section{3 本征硅薄膜对硅片的钝化}

硅片的少子寿命 $(\tau)$ 是表征界面态最直接有效 的参数, 为了研究硅烷浓度对本征硅薄膜针化性能 的影响, 实验在硅片的正、反表面沉积了一系列厚 约 $10 \mathrm{~nm}$ 不同硅烷浓度的本征硅薄膜, 并测试了不

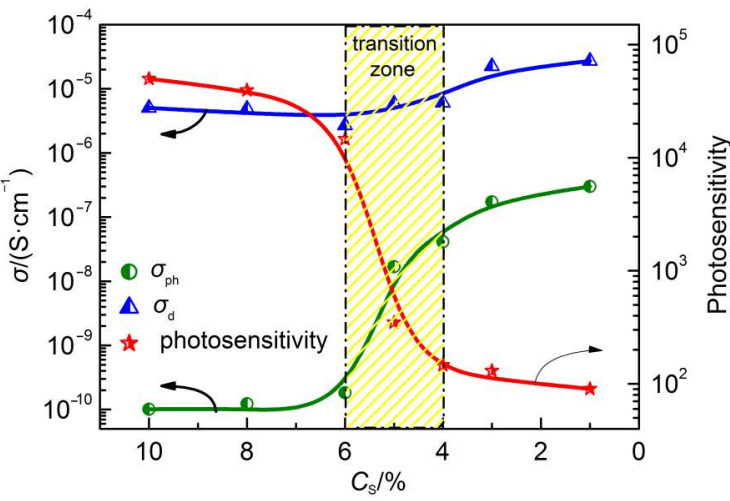

图 6 不同硅烷浓度下薄膜的电导率及光敏性

Fig.6 Conductivity and photosensitivity of films with different silane concentrations $\sigma_{\mathrm{ph}}$ : photoconductivity; $\sigma_{\mathrm{d}}$ : dark conductivity

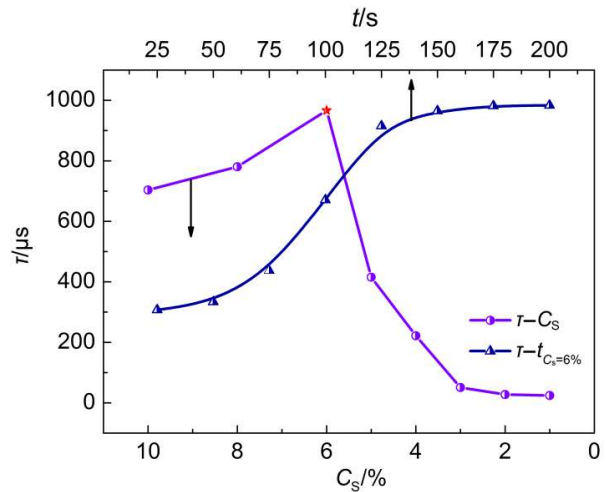

图 7 少子寿命 $(\tau)$ 随本征硅薄膜硅烷浓度和沉积时间 (厚度)的变化

Fig.7 Minority carrier lifetime $(\tau)$ as a function of the silane concentration and deposition time (thickness) of intrinsic silicon films

同样品的少子寿命. 硅片的少子寿命随本征硅薄膜 硅烷浓度变化的曲线如图 7 所示. 由图可见, 当 $C_{\mathrm{S}}>$ $6 \%$ 时, 随着硅烷浓度的降低, 硅片的少子寿命逐渐 增高, 且在 $C_{\mathrm{s}}=6 \%$ 时达到最大值, $\tau=966 \mu \mathrm{s}$; 继续降 低硅烷浓度, 硅片的少子寿命出现急剧下滑, 当 $C_{\mathrm{S}}=$ $3 \%$ 时, 硅片的少子寿命仅为 $51 \mu \mathrm{s}$, 之后硅片少子寿 命的变化逐渐趋于稳定. 以上结果表明, 当本征硅 薄膜处于非晶态时, 薄膜对硅片表面具有相对较好 的针化效果, 而且靠近过渡区的薄膜 $\left(C_{\mathrm{S}}=6 \%\right.$ 附近 $)$ 钝化性能最好, 而薄膜一旦开始晶化, 随着晶化度 的逐渐加强, 薄膜的钝化性能就会急剧下降, 即本 征纳米晶硅薄膜对硅片表面具有较差的钝化能力. 为解释以上实验结果, 需要考虑本征硅薄膜的微结 构、氢含量及其成键方式. 由前面 FTIR 分析结果可 知, 本征非晶硅薄膜中的氢含量明显高于纳米晶硅 薄膜, 且成键方式以 $\mathrm{SiH}$ 键为主. 比较图 7 与图 4 还 可以发现, 硅片的少子寿命与本征硅薄膜中氢含量 随硅烷浓度变化的趋势基本一致. 这表明, 非晶硅 薄膜中由于含有大量以 $\mathrm{SiH}$ 形式成键的氢原子, 可 以有效钝化硅片表面的悬挂键缺陷, 因此具有较好 的钝化效果. 文献 ${ }^{25}$ 指出, 处于致密非晶硅薄膜内的 $\mathrm{SiH}$ 键更有利于钝化晶硅表面, 与本文的实验结果 一致. 由于 $C_{\mathrm{S}}=6 \%$ 附近靠近过渡区的薄膜不仅氢含 量最高, 结构因子也最低, 薄膜具有较好的致密性, 带隙态密度低, 因此表面钝化能力最好. 另外, 在 $C_{\mathrm{s}}<6 \%$ 的条件下, 纳米晶硅薄膜生成, 而当硅烷浓度 很低(氢稀释很高)时, 尤其对 c-Si(100)衬底而言, 很 容易在硅片表面生长硅外延层, 使硅片的少子寿命 大大降低, 这可能也是纳米晶硅薄膜钝化性能急剧 
下降的重要原因之一.

本征硅薄膜的厚度对硅片表面的针化也有很 重要的影响. 实验在 $C_{\mathrm{S}}=6 \%$ 的条件下, 在硅片上沉 积了一系列不同厚度的本征硅薄膜, 以对本征硅针 化层做进一步优化. 薄膜厚度以沉积时间表征, 不 同样品的少子寿命如图 7 所示. 从图中可以看到, 随 着本征硅薄膜厚度的增加, 硅片的少子寿命先单调 增加, 之后又趋于饱和. 这可能是由于当薄膜厚度 过小时, 薄膜的均匀性和质量都较差, 使具有线面 结构的硅片表面不能得到很好的覆盖及针化, 因而 硅片少子寿命较低. 随着厚度的增加, 薄膜的均匀 性和质量明显改善, 钝化质量明显提高, 当薄膜达 到一定厚度 $(\sim 8 \mathrm{~nm})$, 也即沉积时间达到 $125 \mathrm{~s}$ 后, 薄 膜的质量趋于稳定, 从而使硅片的少子寿命趋于饱 和.

\section{4 本征硅薄膜钝化层对 SHJ 电池性能的影响}

实验以不同硅烷浓度的本征硅薄膜作为钝化 层, 制备了一系列 nc-Si:H(p)/c-Si $(n) \mathrm{SHJ}$ 太阳电池, 电池结构为 $\mathrm{Al} / \mathrm{ITO} / \mathrm{nc}-\mathrm{Si}: \mathrm{H}(p) / \mathrm{a}-\mathrm{Si}: \mathrm{H}(\mathrm{i}) / \mathrm{c}-\mathrm{Si}(n) / \mathrm{c}-\mathrm{Si}$ $(n+) / \mathrm{Al}$, 本征硅薄膜钝化层的厚度均为 $10 \mathrm{~nm}$ 左右. 本征钝化层硅烷浓度对电池开路电压的影响如图 8 所示. 可以看到, 图中电池开压随钝化层硅烷浓度 的变化与图 7 中硅片少子寿命的变化趋势一致. 当 钝化层的硅烷浓度为 $6 \%$ 时, 硅片的少子寿命最高, 电池的开路电压也最高, $V_{\mathrm{oc}}=677 \mathrm{mV}$. 对于 $\mathrm{SHJ}$ 太阳 电池, 开路电压与载流子在硅表面载流子的复合速 率的关系为: ${ }^{26}$

$$
V_{\mathrm{oc}}=\frac{1}{q}\left\{\Phi_{\mathrm{c}}-A k T \ln \left(\frac{q N_{\mathrm{c}} S_{\mathrm{it}}}{J_{\mathrm{sc}}}\right)\right\}
$$

式中, $\Phi_{\mathrm{c}}$ 为异质结界面的势垒高度, $N_{\mathrm{c}}$ 为硅片祄底 导带的有效态密度, $J_{\mathrm{sc}}$ 为短路电流密度, $A$ 为二极管

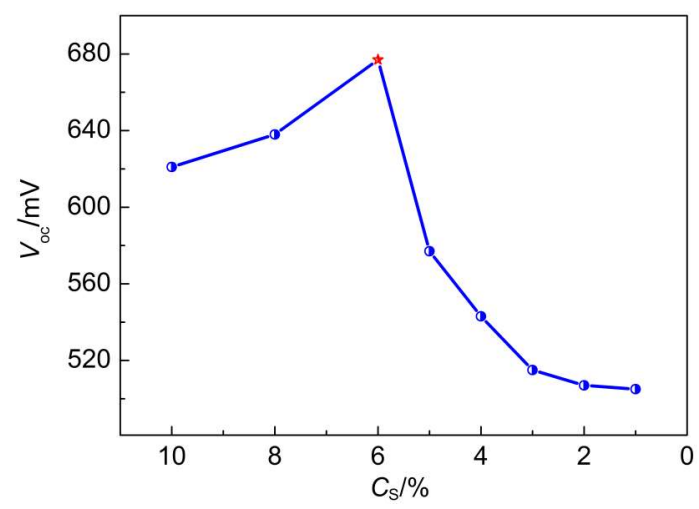

图 8 开路电压 $\left(V_{\mathrm{oc}}\right)$ 随本征钝化层硅烷浓度的变化

Fig.8 Open circuit voltage $\left(V_{\text {oc }}\right)$ as a function of the silane concentration of intrinsic passivation layers
理想因子, $S_{\mathrm{it}}$ 为载流子在异质结界面的复合速率, 与 少子寿命成反比. 由上式可知, 硅片的少子寿命越 高, 复合速率越低, 电池的开路电压就越高, 可以很 好地解释本实验结果.

图 9 为以 $C_{\mathrm{s}}=6 \%$ 的非晶硅薄膜为钝化层, 沉积 时间分别为 $50 、 125 、 200 \mathrm{~s}$ 的 nc- $\mathrm{Si}: \mathrm{H}(p) / \mathrm{c}-\mathrm{Si}(n) \mathrm{SHJ}$ 电池的电流密度-电压 $(J-V)$ 特性曲线, 电池的各项 输出参数见表 2 . 可以看到, 对于沉积时间为 $50 \mathrm{~s}$ 的 钝化层 $(<2 \mathrm{~nm})$, 电池的填充因子和开路电压很低, 这主要是由于薄膜的厚度过小, 薄膜不均匀而且质 量非常差, 不能有效钝化硅片的线面表面, 从而使 电池中的漏电流增大, 并联电阻减小, 导致电池的 填充因子和开路电压降低; 而对于沉积时间为 $200 \mathrm{~s}$ 的本征硅针化层 $(13 \mathrm{~nm})$, 因其使硅片的少子寿命 大大提高, 电池的开路电压也因此得到大幅提升 $\left(V_{o c}=681 \mathrm{mV}\right)$, 但另一方面, 由于薄膜厚度增加, 电池 的串联电阻增加, 同时还增加了钝化层对可见光范 围的光吸收, 使进入硅祄底的光子流减少, 从而导 致电池的短路电流减小. 图 10 为针化层的沉积时间 分别为 $125 \mathrm{~s}(\sim 8 \mathrm{~nm})$ 和 $200 \mathrm{~s}(\sim 13 \mathrm{~nm})$ 时, $\mathrm{nc}-\mathrm{Si}: \mathrm{H}$ $(p) / \mathrm{c}-\mathrm{Si}(n) \mathrm{SHJ}$ 电池的 $\mathrm{QE}$ 响应曲线. 从图中可以看

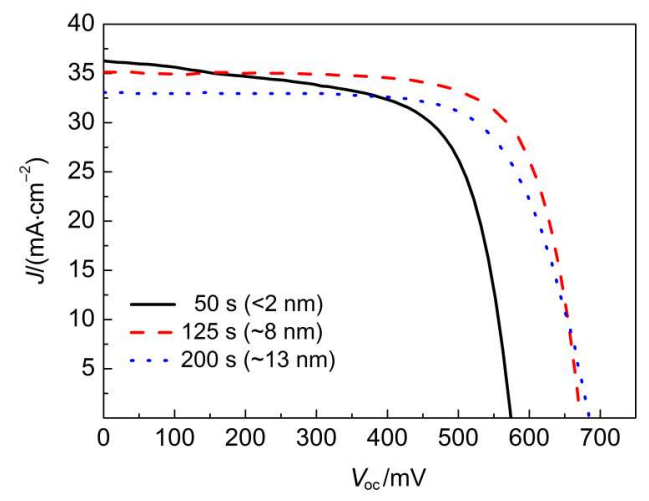

图9 本征层厚度不同的 nc-Si:H $(p) / \mathrm{c}-\mathrm{Si}(n) \mathrm{SHJ}$ 太阳电池电流密度-电压 $(J-V)$ 曲线

Fig.9 Current density-voltage $(J-V)$ curves of nc-Si:H(p)/ c-Si(n) SHJ solar cells with different i-layer thicknesses

表 2 本征层厚度不同的 nc-Si:H/c-Si SHJ 太阳 电池性能参数

Table 2 Parameters of nc-Si:H/c-Si SHJ solar cells with different $\mathrm{i}$-layer thicknesses

\begin{tabular}{rcccc}
\hline$t / \mathrm{s}$ & $J_{\mathrm{sc}} /\left(\mathrm{mA} \cdot \mathrm{cm}^{-2}\right)$ & $V_{\mathrm{oc}} / \mathrm{mV}$ & $\mathrm{FF}$ & $\eta / \%$ \\
\hline 50 & 36.3 & 571 & 0.66 & 13.7 \\
125 & 35.1 & 672 & 0.73 & 17.3 \\
200 & 33.1 & 684 & 0.71 & 16.1 \\
\hline
\end{tabular}

$J_{\text {sc: }}$ short circuit current density; $V_{\text {oc }}$ : open circuit voltage; FF: fill factor, $\eta$ : efficiency 


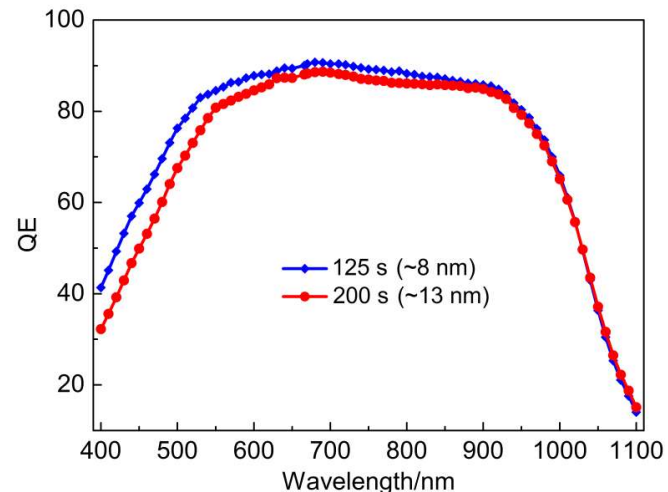

图 10 本征层厚度不同的 $\mathrm{nc-Si}: \mathrm{H}(p) / \mathrm{c}-\mathrm{Si}(n) \mathrm{SHJ}$ 太阳电池量子效率 $(\mathbf{Q E})$ 曲线

Fig.10 Quantum efficiency (QE) curves of nc-Si:H(p)/ c-Si(n) SHJ solar cells with different i-layer thicknesses

出, 随着本征钝化层厚度的增加, 薄膜在 400-600 $\mathrm{nm}$ 范围的光吸收增加, 从而导致电池在该波段的光 谱响应明显降低, 短路电流减小. 当本征层的沉积 时间为 $125 \mathrm{~s}$ 时, 此时薄膜的厚度适中, 同时也能很 好的钝化硅片表面, 因而该条件下制备的电池效率 最高, $\eta=17.3 \%\left(V_{\mathrm{oc}}=672 \mathrm{mV}, J_{\mathrm{sc}}=35.1 \mathrm{~mA} \cdot \mathrm{cm}^{-2}, \mathrm{FF}=\right.$ $0.73)$.

\section{4 结 论}

本文用 RF-PECVD在低温、低功率的条件下制 备了一系列不同硅烷浓度的本征硅薄膜, 研究了硅 烷浓度对薄膜的微结构、光电性能及表面针化性能 的影响, 并将本征硅薄膜作为针化层应用到 nc-Si:H $(p) / \mathrm{c}-\mathrm{Si}(n) \mathrm{SHJ}$ 电池中, 研究了硅烷浓度和薄膜厚度 其对电池性能的影响. 结果表明, 随着硅烷浓度的 降低(氢稀释的增加), 本征硅薄膜逐渐由非晶相过 渡到纳米晶相, 硅烷浓度 $C_{\mathrm{S}}>6 \%$ 时为非晶硅薄膜, $C_{\mathrm{s}}=6 \%-4 \%$ 为过渡区薄膜, $C_{\mathrm{s}}<3 \%$ 为纳米晶硅薄膜. 薄膜的晶化率、氢含量和光敏性在三个相区都呈慢快-慢的变化趋势, 薄膜的结构因子和光学带隙在硅 烷浓度降低到 $6 \%$ 以后迅速增大; 本征硅薄膜的钝 化性能由薄膜的氢含量及氢的成键方式决定. 在 $C_{\mathrm{s}}=6 \%$ 附近靠近过渡区的本征非晶硅薄膜氢含量最 高, 结构因子最低, 光电性能良好, 且主要以 $\mathrm{SiH}$ 形 式成键, 对硅片表现出优异的钝化性能, 使电池的 开路电压大幅提高. 但是, 当薄膜的厚度过小时, 会 严重影响其钝化质量. 本实验中, 以 $C_{\mathrm{s}}=6 \%$ 的本征 硅薄膜为针化层, 在薄膜厚度为 $8 \mathrm{~nm}$ 时所制备 $\mathrm{SHJ}$ 电池的性能最好. 实验最终制得了 $V_{\mathrm{oc}}=672 \mathrm{mV}$, $J_{\mathrm{sc}}=35.1 \mathrm{~mA} \cdot \mathrm{cm}^{-2}, \mathrm{FF}=0.73, \eta=17.3 \%$ 的 $\mathrm{nc}-\mathrm{Si}: \mathrm{H}(p) / \mathrm{c}-$
$\operatorname{Si}(n)$ SHJ 太阳电池.

\section{References}

(1) Wang, L. G.; Zhang, X. D.; Wang, F. Y.; Wang, N.; Jiang, Y. J.; Hao, Q. Y.; Xu, S. Z.; Wei, C. C.; Zhao, Y. Acta Phys. -Chim. Sin. 2014, 30 (9), 1758. [王利果, 张晓丹, 王奉友, 王 宁, 姜 元建, 郝秋艳, 许盛之, 魏长春, 赵 颖. 物理化学学报, 2014, 30 (9), 1758.] doi: 10.3866/PKU.WHXB201406301

(2) Zeman, M.; Zhang, D. Heterojunction Silicon Based Solar Cells. In Physics and Technology of Amorphous-Crystalline Heterostructure Silicon Solar Cells; Springer: Verlag, Berlin, Heidelberg, 2012; pp 13-43.

(3) De Wolf, S.; Demaurex, B.; Descoeudres, A.; Ballif, C. Phys. Rev. B 2011, 83 (23), 233301. doi: 10.1103/ PhysRevB.83.233301

(4) Zhao, L.; Zhou, C.; Li, H.; Diao, H.; Wang, W. Sol. Energy Mater. Sol. Cells 2008, 92 (6), 673. doi: 10.1016/j. solmat.2008.01.018

(5) Dao, V. A.; Heo, J.; Choi, H.; Kim, Y.; Park, S.; Jung, S.; Lakshminarayan, N.; Yi, J. Sol. Energy 2010, 84 (5), 777. doi: 10.1016/j.solener.2010.01.029

(6) Kim, S.; Dao, V. A.; Lee, Y.; Shin, C.; Park, J.; Cho, J.; Yi, J. Sol. Energy Mater. Sol. Cells 2013, 117, 174. doi: 10.1016/j. solmat.2013.05.042

(7) Gogolin, R.; Ferré, R.; Turcu, M.; Harder, N. P. Sol. Energy Mater. Sol. Cells 2012, 106, 47. doi: 10.1016/j. solmat.2012.06.001

(8) Gielis, J.; Van Den Oever, P.; Hoex, B.; Van De Sanden, M.; Kessels, W. Phys. Rev. B 2008, 77 (20), 205329. doi: 10.1103/ PhysRevB.77.205329

(9) Descoeudres, A.; Barraud, L.; De Wolf, S.; Strahm, B.; Lachenal, D.; Guérin, C.; Holman, Z.; Zicarelli, F.; Demaurex, B.; Seif, J. Appl. Phys. Lett. 2011, 99 (12), 123506. doi: 10.1063/ 1.3641899

(10) Mews, M.; Schulze, T. F.; Mingirulli, N.; Korte, L. Appl. Phys. Lett. 2013, 102 (12), 122106. doi: 10.1063/1.4798292

(11) Qiao, Z.; Xie, X.; Hao, Q.; Wen, D.; Xue, J.; Liu, C. Appl. Surf. Sci. 2015, 324, 152. doi: 10.1016/j.apsusc.2014.10.091

(12) Dong, L. L.; Wang, Y. Y.; Tong, X. L.; Jin, G. Q.; Guo, X. Y. Acta Phys. -Chim. Sin. 2014, 30 (1), 135. [董莉莉, 王英勇, 童 希立, 靳国强, 郭向云. 物理化学学报, 2014, 30 (1), 135.] doi: 10.3866/PKU.WHXB201311052

(13) Kaneko, T.; Wakagi, M.; Onisawa, K. I.; Minemura, T. Appl. Phys. Lett. 1994, 64 (14), 1865. doi: 10.1063/1.111781

(14) He, Y.; Yin, C.; Cheng, G.; Wang, L.; Liu, X.; Hu, G. J. Appl. Phys. 1994, 75 (2), 797. doi: 10.1063/1.356432

(15) Matsuda, A. Thin Solid Films 1999, 337 (1), 1.

(16) Tsai, C.; Anderson, G.; Thompson, R.; Wacker, B. J. Non-Cryst. Solids 1989, 114, 151. doi: 10.1016/0022-3093(89)90096-3

(17) Gope, J.; Kumar, S.; Sudhakar, S.; Lodhi, K.; Rauthan, C.; Srivastava, P. Journal of Alloys and Compounds 2013, 577, 
710. doi: 10.1016/j.jallcom.2013.05.142

(18) Kroll, U.; Meier, J.; Shah, A.; Mikhailov, S.; Weber, J. J. Appl. Phys. 1996, 80 (9), 4971. doi: 10.1063/1.363541

(19) Zhang, S.; Liao, X.; Raniero, L.; Fortunato, E.; Xu, Y.; Kong, G.; Aguas, H.; Ferreira, I.; Martins, R. Sol. Energy Mater. Sol. Cells 2006, 90 (18), 3001.

(20) Ray, S.; Mukhopadhyay, S.; Jana, T.; Carius, R. J. Non-Cryst. Solids 2002, 299, 761.

(21) Chang, T. H.; Chang, J. Y.; Chu, Y. H.; Lee, C. C.; Chen, I. C.; Li, T. Surf. Coat. Technol. 2013, 231, 604. doi: 10.1016/j. surfcoat.2012.10.008

(22) Bakr, N.; Funde, A.; Waman, V.; Kamble, M.; Hawaldar, R.; Amalnerkar, D.; Sathe, V.; Gosavi, S.; Jadkar, S. J. Phys. Chem. Solids 2011, 72 (6), 685. doi: 10.1016/j.jpcs.2011.02.019

(23) Waman, V.; Kamble, M.; Pramod, M.; Funde, A.; Sathe, V.;
Gosavi, S.; Jadkar, S. In Structural and Optical Investigations of nc-Si:H Thin Films Prepared by Hot-Wire Method; American Institute of Physics Conference Series, 2011; pp 155-157.

(24) VavruHková, V.; Müllerová, J.; Srnánek, R.; Šutta, P. Vacuum 2009, 84 (1), 123. doi: 10.1016/j.vacuum.2009.05.022

(25) Zhao, L.; Diao, H. W.; Zeng, X. B.; Zhou, C. L.; Li, H. L.; Wang, W. J. Study on the Passivation Effect of the Crystalline Silicon Thin Film Surface. In Proceeding of 10th Solar Photovoltaic Conference-Welcome to Solar PV New Era; Zhejiang University Press: Hangzhou, 2008; pp 64-67. [赵 雷, 习宏伟, 曾湘波, 周春兰, 李海玲, 王文静. 晶硅表面薄膜硅 钝化效果研究. In 第十届中国太阳能光伏会议论文集: 迎接光 伏发电新时代, 杭州: 浙江大学出版社, 2008: 64-67.]

(26) Jensen, N.; Hausner, R.; Bergmann, R.; Werner, J.; Rau, U. Prog. Photovoltaics Res. Appl. 2002, 10 (1), 1. 